\title{
Estimation of mixed-layer depth from surface parameters
}

\author{
by D. Swain ${ }^{1}$, M. M. Ali ${ }^{1,2}$ and R. A. Weller ${ }^{3}$
}

\begin{abstract}
Mixed layer depth (MLD) is an important oceanographic parameter. However, the lack of direct observations of MLD hampers both specification and investigation of its spatial and temporal variability. An important alternative to direct observation would be the ability to estimate MLD from surface parameters easily available from satellites. In this study, we demonstrate estimation of MLD using Artificial Neural Network methods and surface meteorology from a surface mooring in the Arabian Sea. The estimated MLD had a root mean square error of $7.36 \mathrm{~m}$ and a coefficient of determination $\left(R^{2}\right)$ of 0.94 . About $67 \%(91 \%)$ of the estimates lie within $\pm 5 \mathrm{~m}( \pm 10 \mathrm{~m})$ of the MLD determined from temperature sensors on the mooring.
\end{abstract}

\section{Introduction}

Ocean mixed layer depth (MLD) is an important parameter that defines the quasihomogenous region of the upper ocean, where physical properties like density, salinity and temperature are nearly constant with depth. MLD variability is important to acoustic propagation (Sutton et al., 1993), ocean-biology (Fasham, 1995), long-term climate change (Thomson and Fine, 2003), and understanding air-sea interactions (Chen et al., 1994a) associated with the exchange of heat, carbon dioxide, and fresh water and with other biological and physical processes. Studies of atmospheric and oceanic phenomena like cyclogenesis, cyclone tracks, heat transport, and fisheries variability also benefit from information on MLD. The rate of intensification of cyclones, for example, is sensitive to the initial MLD distribution (Mao et al., 2000).

MLD can be estimated from in situ temperature and/or density profiles. Monterey and Levitus (1997), Rao et al. (1991), Rao (1986), Ali and Sharma (1994), Ali et al. (1987), and Belkin and Filyushkin (1986) used temperature profiles to estimate MLD. Some investigators refer this parameter estimated from temperature profiles alone as isothermal layer depth (e.g., Bathen, 1972; Lukas and Lindstrom, 1991; Richards et al., 1995; Obata et al., 1996; Kara et al., 2000; Kara et al., 2003). Thomson and Fine (2003), Bathen (1972), Levitus (1982) and Kara et al. (2000) used density profiles, and Montégut et al. (2004)

1. Oceanography Division, National Remote Sensing Agency, Balanagar, Hyderabad 500037, India.

2. Corresponding author.email: mmali73@yahoo.com

3. Physical Oceanography Department, Woods Hole Oceanographic Institution, Woods Hole, Massachusetts, 02543, U.S.A. 
used both temperature and density profiles to estimate MLD. Since the in situ profiles are sparse due to the limited availability of measurements from ships and ocean data buoys, several numerical models like 1-D mixed layer models (Niiler and Krauss, 1977; Price et al., 1986; Chen et al., 1994b) and 3-D models (Mechoso et al., 1995; Godfrey and Schiller, 1997; Schiller et al., 1997) have been used to provide an alternate means to estimate MLD and overcome the limited availability of upper ocean temperature and density data. However, one of the main problems of implementing even the best of the ocean models to estimate MLD is the complexity of physical, chemical and biological processes involved and the uncertainty about the realism of the models' simulation of upper ocean vertical structure. One other alternate, linear statistical techniques like multiple regression technique (MRT), is also likely to fail to capture the complexity of the relationship between surface forcing and upper ocean response. For a complex process like mixed layer dynamics, a nonlinear model like artificial neural networks (ANN) may be more appropriate. The aim of the present study is to demonstrate the estimation of MLD from surface observations alone using the ANN approach and to quantify how well this approach works in comparison to the MRT method.

Working in the equatorial Indian Ocean, Ali (1993) and Ali and Sharma (1994) developed a statistical relation between MLD and sea-surface height (SSH). These studies used only SSH to estimate MLD and were restricted to the equatorial Indian Ocean. More typically, MLD depends upon many other surface parameters besides the heat advection associated with the geostrophic transports captured by SSH. In this study, we consider sea-surface temperature (SST), wind stress (WS) and dynamic height (DH). We did not consider the subsurface heat advection, radiation and surface heat fluxes because our main aim is to demonstrate the estimation of MLD from those surface parameters that can be directly obtained from remote sensing platforms. In this study we used observations from an Arabian Sea mooring as a proxy for those remotely sensed data. We considered DH as a surface parameter, though it is computed from the subsurface temperature and salinity profiles, because this parameter can be replaced with SSH available from altimeters.

\section{Data and methodology}

The surface mooring data came from the central Arabian Sea mooring located at $15.5 \mathrm{~N}$ and 61.5E, deployed by the Woods Hole Oceanographic Institution during 16 October 1994-22 October 1995. Rudnick et al. (1997) and Ali et al. (2004) have given the details of the instrumentation on this mooring and its observations. We selected these data for the analysis, even though observations are during 1994-1995, as this is the only data set with both meteorological and oceanographic observations in the Indian Ocean with continuous time series with hourly sampling. Note that the value of hourly sampling for us is that we have a large number of total samples. We are not, given the present lack of availability of remote sampling methods that resolve the diurnal cycle in the surface forcing of the ocean, working to resolve diurnal variability in MLD.

Out of the 8858 hourly observations, we used 8306 profiles for which all surface and 
subsurface measurements are available. While temperature observations are available at 30 depths (only those depths where observations are available throughout the study period), salinity observations are available only at 6 depths $(1.42,10,35,100,200 \& 250 \mathrm{~m})$. DH at the surface relative to $250 \mathrm{~m}$ depth was computed from temperature and salinity profiles. In the first step, MLD was estimated from the temperature profiles using the gradient criterion (Ali et al., 1987). In this method MLD is the depth where the temperature gradient exceeds $0.08^{\circ} \mathrm{C} / \mathrm{m}$. We refer to this MLD based on in situ temperature data as $\mathrm{MLD}_{\mathrm{IS}}$. The authors are aware of the limitations of estimation of MLD from temperature profiles alone. However, we could not compute MLD using the density criterion, which also includes salinity contributions (Lewis et al., 1990) as the vertical resolution of the salinity observations is too sparse. We then estimated the temperature profiles using ANN method following Ali et al. (2004). They used a multi-layer perceptron model employing the back propagation algorithm to estimate sub-surface temperature profiles. We also computed MLD from these ANN-estimated profiles using the temperature gradient criterion discussed above. We refer to the MLD estimated from the ANN-estimated temperature profiles as $\mathrm{MLD}_{\mathrm{AT}}$. In addition to these two methods, we computed MLD directly from surface parameters using the ANN approach, $\mathrm{MLD}_{\mathrm{AA}}$, and using the MRT, referred henceforth as $\mathrm{MLD}_{\mathrm{RT}}$. These two methods are described in the following section.

\section{Artificial neural network and multiple regression analyses}

The advent of high performance computers and the use of modern computational techniques have provided new methods for use in oceanographic studies. The use of Fuzzy Logic, ANN, Genetic Algorithm and Fractals, for example, in addition to statistical ensemble models and conventional methods holds promise. ANN has been widely used in various meteorological (Badran et al., 1991; Butler et al., 1996; French et al., 1992; Liu et al., 1997) and oceanographic (Derr and Slutz, 1994; Hsieh and Tang, 1998; Tangang et al., 1998; Krasnopolsky et al., 2002; Ali et al., 2004, Tolman et al., 2005) studies. The ANN technique was also used in studying atmospheric radiation processes (Krasnopolsky, 1997; Chevallier et al., 1998; Chevallier et al., 2000; Krasnopolsky et al., 2005) and in developing satellite retrieval procedures (Krasnopolsky et al., 1995; Krasnopolsky and Schiller, 2003).

An ANN is a massive parallel-distributed computer model consisting of simple processing units called artificial neurons (henceforth referred simply as neurons) which are the basic functioning units. The neurons are modeled as mathematical functions with analogy to the neurons (cells) present in the biological brain (Fig. 1). These neurons are interconnected through activation links modulated by weights called connection weights or synoptic weights. The simplest neuron may be mathematically represented by:

$$
y=f(\operatorname{bias}+w 1 * x 1+w 2 * x 2+w 3 * x 3+\cdots+w n * x n)
$$




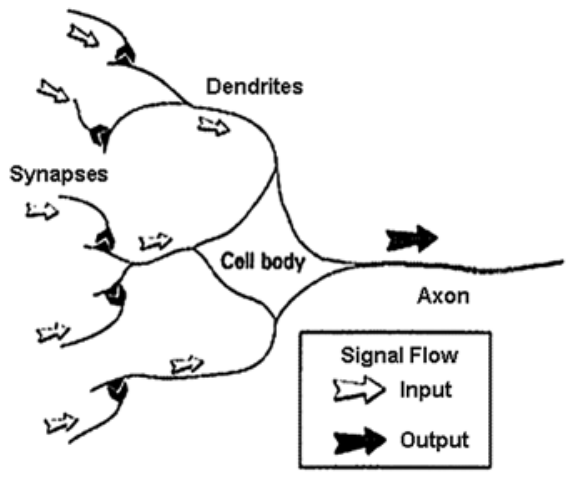

a

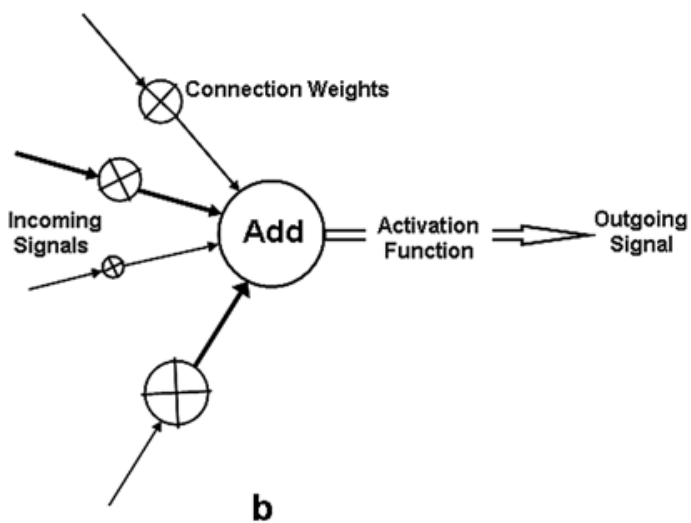

b

Figure 1. (a) A Biological Neuron, and (b) An Artificial Neuron (Source: Gurney, 1997).

where, $y$ is the output, $x 1, x 2$, etc., are the inputs ( $n$ is the number of inputs) and $f$ is the activation function. The resulting network has a natural propensity to store experimental knowledge through learning or training (Haykin, 2002).

The neural network formulation is based on the fact that any parameterization of a process can be considered as a continuous or almost continuous (with finite discontinuities) mapping (input versus output vector dependence), which is analogous to atmospheric and ocean models with forcing(s) and response. The ANN is a generic tool for approximating such mappings (Cybenko, 1989; Funahashi, 1989; Hornik 1991; Chen and Chen, 1995a,b; Attali and Pagès, 1997). Based on this, ANN can be expressed as an analytical approximation that uses a family of functions (more significantly, these can be a combination of linear and nonlinear threshold functions, known as activation functions) which may be generally of the form:

$$
Y_{q}=A_{q 0}+\sum_{j=1}^{k} A_{q j} \Phi\left(B_{j 0}+\sum_{i=1}^{n} B_{j i} X_{i}\right), q=1,2, \ldots, m
$$

where $X_{i}$ and $Y_{q}$ are the components of the input and output vectors respectively, and $A$ and $B$ are fitting parameters. $\Phi$ is the activation function, $n$ and $m$ are the number of inputs and outputs, respectively, and $k$ is the number of neurons in the layer (Ripley, 1997; Krasnopolsky et al., 2005). The hidden layer is an internal layer between the input and output layer containing many of the neurons in various inter-connected structures. All the complex mathematical computations as required for the ANN model formulation are carried out by the neurons present in this layer and the results are transmitted to the output layer.

An ANN can be broadly classified into two main categories based on its topology: networks with single-hidden layer and networks with multiple hidden layers. Some of the popular formulations of ANN models are Multi Layer Perceptron (MLP), Radial basis 


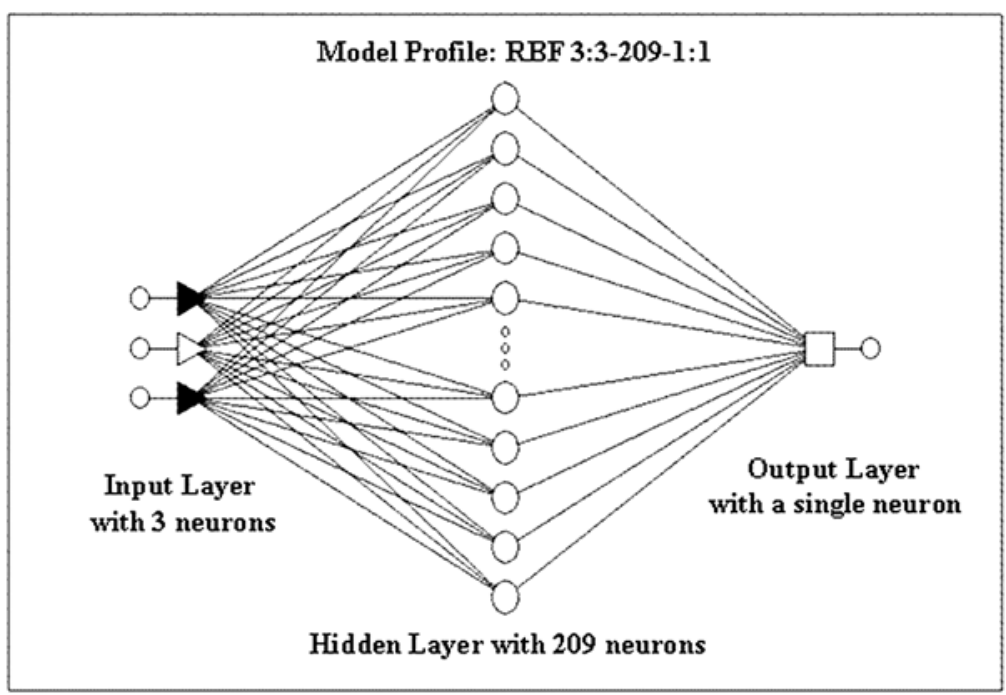

Figure 2. The ANN model architecture used in the present study.

functions (RBF), and Conjugate Gradient Descent models (Broomhead and Lowe, 1988; Moody and Darkin, 1989; Haykin, 2002). In the present analysis we used a single output ANN model based on RBF, employing the Pseudo-Invert algorithm.

The RBF model consists of one input layer, one output layer and one hidden layer of radial units. In a RBF, network units respond nonlinearly to the distance of points from the center represented by the radial unit. Radial unit refers to a neuron based on the RBF formulation where the first computation performed by the unit (i.e. the neuron) is to compute the "radial distance," $d$, between the input vector $x i$ and the center of the basis function using Euclidean distance. This converts the input into a higher dimension after which it can be classified using only one layer of neurons with linear activation functions. The network architecture consists of a single hidden layer of radial units (nonlinear activation functions) and an output layer of linear units (linear activation functions). The ANN model architecture (RBF network) used in the present study has one input layer consisting of three neurons, one output layer consisting of a single neuron and one hidden layer with 209 hidden neurons (Fig. 2).

The ANN analysis requires three data sets: (1) Training (Learning), (2) Verification (Validation), and (3) Prediction (Testing). The data set marked for training is used to train the ANN model through several iterations. The verification set of data is used to validate the model during this process so that the model does not over-fit during training. At this stage the ANN verifies whether the model developed for the training data set holds good outside the data set also, in terms of root mean square (RMS) error, and applies a mid-term correction in case required. The trained ANN model is then stored and used for estimating/ predicting the output using the input parameters from the data set marked for Prediction. 
The MLD predicted by the ANN model using the input parameters is compared with $\mathrm{MLD}_{\mathrm{IS}}$ of the data set marked for prediction.

In the present analysis, the input (independent) parameters are SST, WS and DH and the dependent parameter (output) is the $\mathrm{MLD}_{\mathrm{IS}}$ for each input set. Out of the selected 8306 hourly observations, we used about $50 \%$ of the data sets (4154 observations) for training the ANN model, about 25\% (2076 sets) for verification, and 25\% (2076 sets) for ANN prediction and validation of the predicted results. In this analysis about $25 \%$ of the data, marked for prediction or testing, were held back and were not used in training the model. We have randomly selected the data sets for training, verification and prediction to avoid any bias that might have crept into the training of the ANN when the training data set is selected on any specific criteria.

ANN yields the best results if the training data set covers a wide spectrum of conditions. From this perspective, it is always advisable to train and validate the model with similar set of observations. A random selection is most suited for an ANN analysis as the training and validation process requires "familiarizing" the network with all possible conditions of inputs and the corresponding target outputs (Haykin, 2002; Ripley, 1997). Richaume et al. (2000); Pozzi et al., (2000); Schroder et al. (2002); Bourras and Liu (2003) used random selection technique for the prediction of various parameters. If the data cover more than one year (one complete cycle), one (or a few) year(s) may be used for training and the other for validation. For example, Singh et al. (2004) used one year of data for the training and the next six months for the prediction. Makarynskyy et al. (2004) used four years of data for the training, the successive four years of data for validation, and the next four years of data for prediction of the sea level variations. Though we have a large data set (hourly observations for one year) for the present analysis, it covers only one year and, in order to cover all the possible oceanographic conditions, data sets for training, validation and prediction have been selected randomly.

For the MRT analysis, we used 6230 observations (those used for training and validation in the ANN analysis) to develop the multiple regression coefficients between $\mathrm{MLD}_{\mathrm{IS}}$ and surface parameters (SST, WS \& DH). The regression equation is: $\mathrm{MLD}=443.78-15.04$ $* \mathrm{SST}+0.55 * \mathrm{WS}+42.18 * \mathrm{DH}$. We estimated $\mathrm{MLD}_{\mathrm{RT}}$ for remaining 2076 observations (that were not used for developing the regression equation) using the above equation. The same 2076 observations were earlier used in predicting MLD using ANN approach. All the results discussed in the subsequent sections refer to the predicted values (2076 hourly observations) from the three estimations.

\section{Results and discussions}

In this analysis, we compare the hourly estimations of $\mathrm{MLD}_{\mathrm{AT}}, \mathrm{MLD}_{\mathrm{AA}}$ and $\mathrm{MLD}_{\mathrm{RT}}$ with $\mathrm{MLD}_{\mathrm{IS}}$ only for 2076 observations that were not used during training the ANN model and during developing the regression equation. The scatter between $M L D_{A A}$ and $M L D_{I S}$ estimations is much better than that obtained from the other two methods (Fig. 3). Statistical analyses of these estimations (Table 1) also indicate better performance by the 

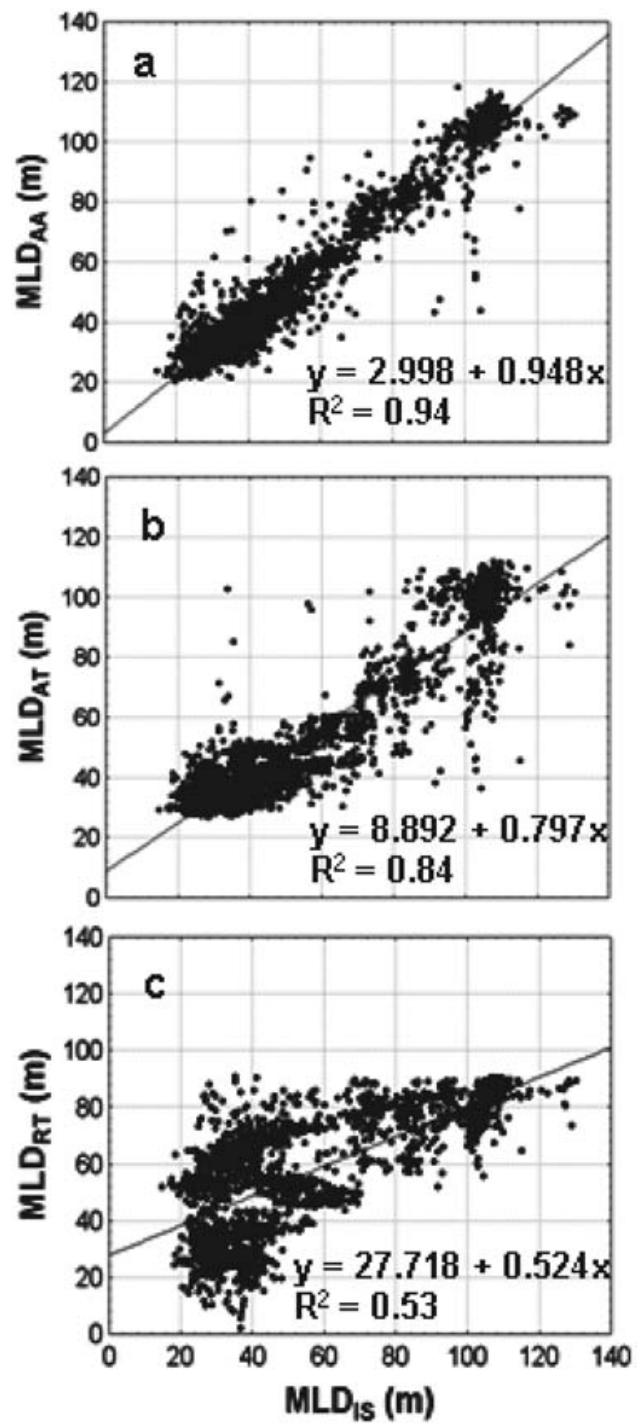

Figure 3. Scatter between MLD estimated from in situ observations $\left(\mathrm{MLD}_{\mathrm{IS}}\right)$ and (a) ANN $\left(\mathrm{MLD}_{\mathrm{AA}}\right)$ (b) ANN estimated temperature profiles $\left(\mathrm{MLD}_{\mathrm{AT}}\right)$ and (c) MRT $\left(\mathrm{MLD}_{\mathrm{RT}}\right)$.

ANN approach compared to MRT and MLD estimated from ANN-based temperature profiles. Ali et al. (2004) reported maximum errors of about $1.8^{\circ} \mathrm{C}$ near the MLD regions in the estimation of temperature profiles. Slight error in temperature profile, particularly, near the MLD region can lead to large errors in the estimation of MLD. Hence, the errors in this parameter obtained from $\mathrm{MLD}_{\mathrm{AT}}$ are large compared to $\mathrm{MLD}_{\mathrm{AA}}$. However, even these estimations are far better than those obtained by MRT $\left(\mathrm{MLD}_{\mathrm{RT}}\right)$. 
Table 1. Statistical analyses of the MLD obtained from ANN (MLD $\left.{ }_{\mathrm{AA}}\right)$, ANN based temperature profiles $\left(\mathrm{MLD}_{\mathrm{AT}}\right)$, and MRT $\left(\mathrm{MLD}_{\mathrm{RT}}\right)$.

Parameters

Data SD (m)

Absolute error mean (m)

Absolute error (\%)

Error SD (m)

SD ratio

$R^{2}$

RMS difference (m)

Bias (m)

Slope

Scatter index
$\mathrm{MLD}_{\mathrm{AA}}$

29.05

4.74

10.35

7.12

0.24

0.94

7.36

$-1.15$

0.93

0.13
$\mathrm{MLD}_{\mathrm{AT}}$

29.05

8.68

17.83

11.66

0.40

0.84

12.62

$-4.00$

0.78

0.22
$\mathrm{MLD}_{\mathrm{RT}}$

29.05

16.70

36.06

19.93

0.69

0.53

20.36

$-0.95$

0.51

0.35

Absolute error mean (average of absolute differences between estimated and in situ), absolute percentage error, standard deviation (SD) of the errors in the estimations (error $\mathrm{SD}$ ), SD ratio (ratio of error SD to data $\mathrm{SD}$ ), coefficient of determination $\left(R^{2}\right)$, RMS difference, and scatter index (RMS error/mean of in situ observations) are much less for $\mathrm{MLD}_{\mathrm{AA}}$ compared to $\mathrm{MLD}_{\mathrm{AT}}$ and $\mathrm{MLD}_{\mathrm{RT}}$ (Table 1). In addition, the slopes in the scatter plots are close to 1 for $\mathrm{MLD}_{\mathrm{AA}}$ (Fig. 3).

Histograms of the errors in MLD estimations from these three methods are shown in Fig. 4. Out of 2076 number of hourly estimations, MLD could be estimated within $\pm 5 \mathrm{~m}$ in about $67 \%(39 \%)$ of the cases where as about $91 \%(68 \%)$ of the estimations lie within \pm 10 $\mathrm{m}$ for $\mathrm{MLD}_{\mathrm{AA}}\left(\mathrm{MLD}_{\mathrm{AT}}\right)$. On the other hand, only $\sim 18 \%(\sim 33 \%)$ of the estimations are within $\pm 5 \mathrm{~m}( \pm 10 \mathrm{~m})$ for $\mathrm{MLD}_{\mathrm{RT}}$.

We have also obtained the monthly average MLD from the $25 \%$ of the randomly selected hourly observations. Thus these monthly means do not actually represent the hourly estimations of the entire month but only $25 \%$ of the values in that particular month. The monthly average $\mathrm{MLD}_{\mathrm{AA}}$ values range from less than $30 \mathrm{~m}$ in April 1995 to a maximum value of $\sim 110 \mathrm{~m}$ in February 1995 (Fig. 5). These estimated values closely follow the in situ measurements over the year while the estimations using MRT have significant deviations ranging from $0.5 \mathrm{~m}$ to $30 \mathrm{~m}$ in individual monthly averages (Fig. 5). Mixed layer is deeper during January to February and again during July. MLD is shallowest during summer and post monsoon seasons. Weller et al. (1998) concluded that much of the mixed layer variability in this region could be explained by local mixed layer processes alone. Deeper MLD during the winter season could be attributed to convective mixing whereas in July, it could be because of strong winds during the Indian summer monsoon.

RMS differences and the absolute percentage errors in the estimation of MLD on monthly basis obtained by averaging randomly selected hourly estimations are shown in Figures 6 and 7, respectively. Monthly RMS differences vary from $4 \mathrm{~m}$ to $\sim 14 \mathrm{~m}$ in case of 


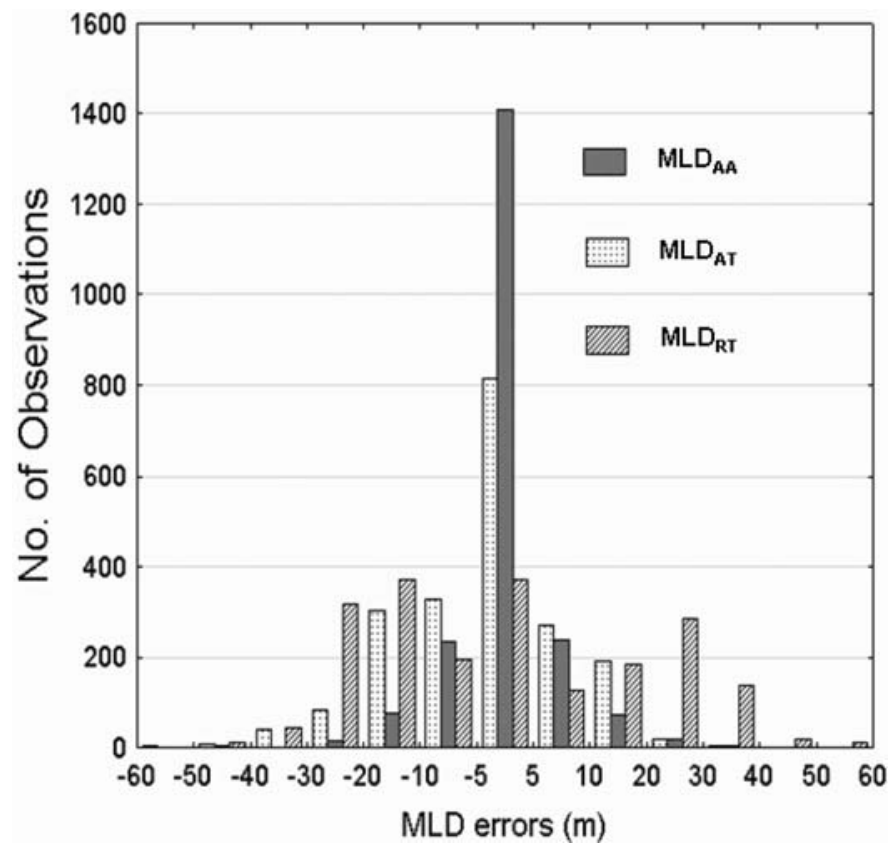

Figure 4. Histograms of errors in the $\mathrm{MLD}_{\mathrm{s}}$ obtained from ANN $\left(\mathrm{MLD}_{\mathrm{AA}}\right)$, ANN estimated temperature profiles $\left(\mathrm{MLD}_{\mathrm{AT}}\right)$ and $\mathrm{MRT}\left(\mathrm{MLD}_{\mathrm{RT}}\right)$.

MLD $_{\text {AA }}$. March, August and September 1995 have larger RMS errors. These values are smaller than those obtained from the MRT. The absolute percentage errors in the case of $\mathrm{MLD}_{\mathrm{AA}}$ are also much less (maximum of $23.5 \%$ ) compared to those obtained from other two methods. The monthly variations of RMS differences and absolute percentage errors are large in the MRT estimations. Even though $\mathrm{MLD}_{\mathrm{AT}}$ closely followed $\mathrm{MLD}_{\mathrm{IS}}$, the errors are large compared to $\mathrm{MLD}_{\mathrm{AA}}$. Further the sensitivity analysis carried out using the ANN model denoted $1^{\text {st }}$ rank sensitivity of MLD to DH followed by SST and WS. The ranking is an indication of the sensitivity of the dependent parameter to variations in the independent parameters. A rank of 1 to DH indicates DH is the parameter affecting the MLD the most followed by SST and the WS.

\section{Summary and conclusions}

Data obtained from a central Arabian Sea mooring located at $15.5 \mathrm{~N}$ and $61.5 \mathrm{E}$ from October 1994 to October 1995 have been used in the present study to estimate MLD from surface parameters. These observations were selected because this is the only data set in the entire Indian Ocean as of today having time series of surface meteorological and subsurface temperature and salinity profiles on hourly basis. $\mathrm{MLD}_{\mathrm{AA}}, \mathrm{MLD}_{\mathrm{AT}}$, and $\mathrm{MLD}_{\mathrm{RT}}$ have been validated with $M L D_{\mathrm{IS}}$. The RMS difference for $\mathrm{MLD}_{\mathrm{AA}}\left(\mathrm{MLD}_{\mathrm{AT}}\right)$ 


\section{Oct-94 Dec-94 Feb-95 Apr-95 Jun-95 Aug-95 Oct-95}

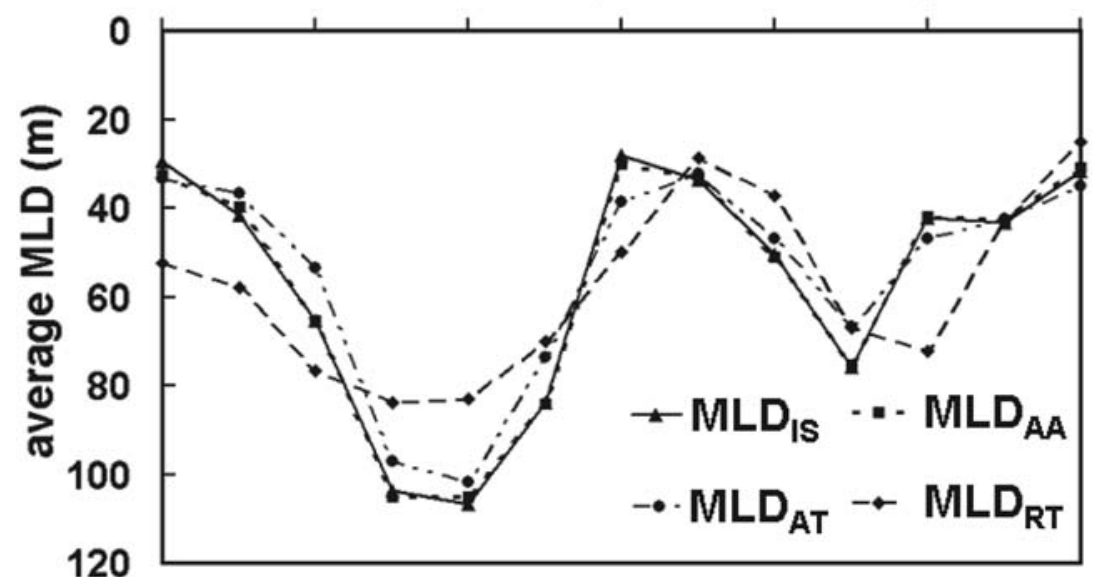

Figure 5. Monthly variation of MLD averaged from estimations from in situ temperature profiles $\left(\mathrm{MLD}_{\mathrm{IS}}\right), \mathrm{ANN}\left(\mathrm{MLD}_{\mathrm{AA}}\right), \mathrm{ANN}$ estimated temperature profiles $\left(\mathrm{MLD}_{\mathrm{AT}}\right)$ and $\mathrm{MRT}\left(\mathrm{MLD}_{\mathrm{RT}}\right)$.

$\left[\mathrm{MLD}_{\mathrm{RT}}\right.$ ] is $7.36 \mathrm{~m}(12.62 \mathrm{~m})$ [20.36 m] with an $R^{2}$ value of $0.94(0.84)$ [0.53]. Less RMS error in $\mathrm{MLD}_{\mathrm{AA}}$ compared to $\mathrm{MLD}_{\mathrm{AT}}$ suggests that it is advisable to train the ANN model directly to estimate MLD from surface parameters rather than estimating the MLD from the estimated temperature profiles.

The main objective of this study has been to demonstrate the estimation of MLD from surface parameters that are directly obtainable from remote sensing platforms. We could not use any remote sensing data in the present study because SSH observations from

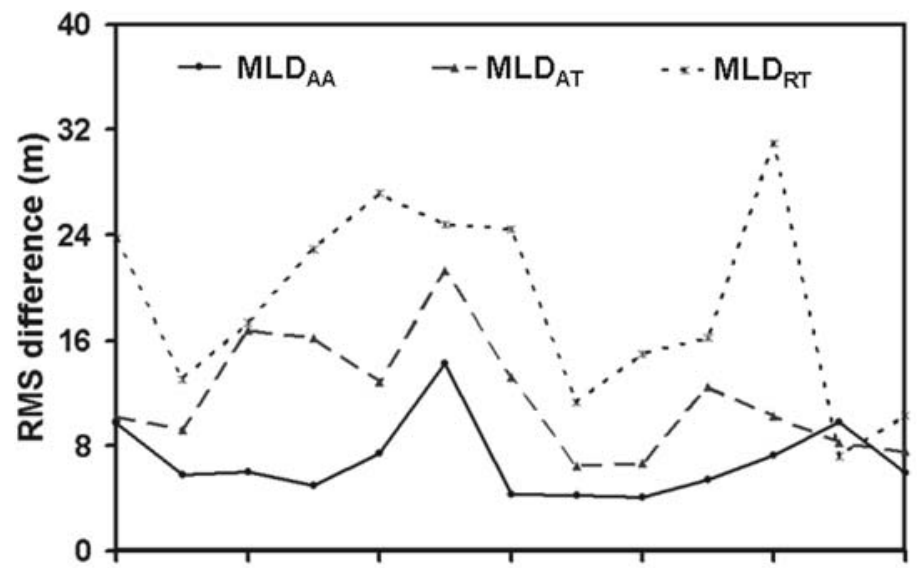

Oct-94 Dec-94 Feb-95 Apr-95 Jun-95 Aug-95 Oct-95

Figure 6. RMS differences in the monthly MLD averages obtained from ANN (MLD $\left.{ }_{\mathrm{AA}}\right)$, ANN based temperature profiles $\left(\mathrm{MLD}_{\mathrm{AT}}\right)$, and MRT $\left(\mathrm{MLD}_{\mathrm{RT}}\right)$. 


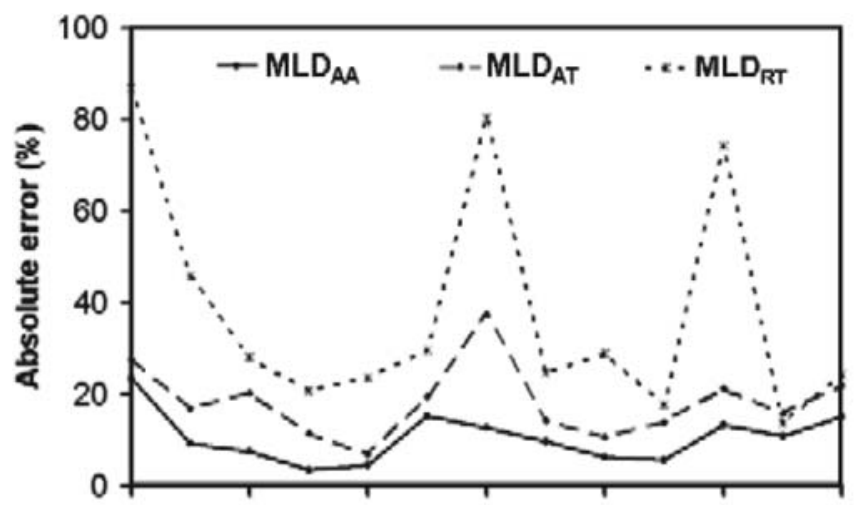

Oct-94 Dec-94 Feb-95 Apr-95 Jun-95 Aug-95 Oct-95

Figure 7. Absolute percentage errors in the monthly MLD averages obtained from ANN $\left(\mathrm{MLD}_{\mathrm{AA}}\right)$, ANN based temperature profiles $\left(\mathrm{MLD}_{\mathrm{AT}}\right)$, and $\mathrm{MRT}\left(\mathrm{MLD}_{\mathrm{RT}}\right)$.

ERS -1 and TOPEX/Poseidon (the two altimeters available during the study period) are too few (all together just 86 observations during the entire study period) to support an ANN approach. Instead, we used the observations from the Arabian Sea mooring as a proxy to the remote sensing parameters. However, the ANN approach that has been used for the first time to estimate MLD from surface parameters alone (SST, WS, and DH), was found to be successful.

DH is used as a surface parameter even though it is computed from temperature and salinity, as this parameter can be easily replaced with SSH from altimeters on board satellites. In future, we plan to carry out a more comprehensive study using surface parameters from remote sensing platforms, including SST from IR/microwave sensors, WS from scatterometers, and SSH from altimeters in conjunction with in situ temperature and salinity profiles from Argo floats and other ocean platforms.

Acknowledgments. This work has been carried out as a part of the Indian National Centre for Ocean Information Services, Department of Ocean Development project. The authors express their gratitude to Dr. R. R. Navalgund, Director, National Remote Sensing Agency, Hyderabad, for critically going through the manuscript and for the suggestions. Discussions with Prof. G. Mitchum, Mr. Asif Iqbal and Dr. A. S. Fischer are gratefully acknowledged. The authors thank the two anonymous reviewers for their critical and constructive comments.

\section{REFERENCES}

Ali, M. M. 1993. Inference of the reversal of mixed layer zonal slope along the Equatorial Indian Ocean using Geosat altimeter data. Int. J. Remote Sens., 14, 2043-2049.

Ali, M. M. and R. Sharma. 1994. Estimation of mixed layer depth in the equatorial Indian Ocean using Geosat altimeter data. Mar. Geo., 17, 63-72.

Ali, M. M., B. Simon and P. S. Desai. 1987. Inference of vertical motion in the equatorial Indian Ocean using satellite data. Oceanologica Acta., 6, 71-76.

Ali, M. M., D. Swain and R. Weller. 2004. Estimation of ocean sub-surface thermal structure from 
surface parameters: A neural network approach. Geophys. Res. Lett., 31, L20308, doi: 10.1029/ 2004GL021192.

Attali, J. G. and G. Pagès. 1997. Approximations of functions by a multilayer perceptron: A new approach. Neural Networks, 6, 1069-1081.

Badran, F., S. Thiria and M. Crepon. 1991. Wind ambiguity removal by the use of neural network techniques. J. Geophys. Res., 96, 20 521-20 529.

Bathen, K. H. 1972. On the seasonal changes in the depth of the mixed layer in the North Pacific Ocean. J. Geophys. Res., 77, 7138-7150.

Belkin, I. M. and B. Filyuskin. 1986. Oceanology, Engl. Transt., 26, 149 pp.

Bourras, D. and W. T. Liu. 2003. Evaluation of latent heat flux fields from satellites and models during SEMAPHORE. J. Appl. Meteorol. 42, 227-239.

Broomhead, D. S. and D. Lowe. 1998. Multivariable functional interpolation and adaptive networks. Complex Systems, 2, 321-355.

Butler, C. T., R. V. Meredith and A. P. Stogryn. 1996. Retrieving atmospheric temperature parameters from DMSP SSM/T-1 data with a neural network. J. Geophys. Res., 101, 7075-7083.

Chen, D., A. J. Busalacchi and L. M. Rothstein. 1994a. The roles of vertical mixing, solar radiation, and wind stress in a model simulation of the sea surface temperature seasonal cycle in the tropical Pacific Ocean. J. Geophys. Res., 99, 20345-20359.

Chen, D., L. M. Rothstein and A. J. Busalacchi. 1994b. A hybrid vertical mixing scheme and its application to tropical ocean models. J. Phys. Oceanog., 24, 2156-2179.

Chen, T. and H. Chen. 1995a. Approximation capability to functions of several variables, nonlinear functional and operators by radial basis function neural networks. Neural Networks, 6, 904-910.

- 1995b. Universal approximation to nonlinear operators by neural networks with arbitrary activation function and its application to dynamical systems. Neural Networks, 6, 911-917.

Chevallier, F., F. Chéruy, N. A. Scott and A. Chédin. 1998. A neural network approach for a fast and accurate computation of longwave radiative budget. J. Appl. Meteor., 37, 1385-1397.

Chevallier, F., J.-J. Morcrette, F. Chéruy and N. A. Scott. 2000. Use of a neural-network-based longwave radiative transfer scheme in the EMCWF atmospheric model. Quart. J. Roy. Meteor. Soc., 126, 761-776.

Cybenko, G. 1989. Approximation by superposition of sigmoidal functions, in mathematics of control. Signals Syst., 2, 303-314.

Derr, V. E. and R. J. Slutz. 1994. Prediction of El Niño events in the Pacific by means of neural networks. AI Applic., 8, 51-63.

Fasham, M. J. R. 1995. Variations in the seasonal cycle of biological production in subarctic oceans: A model sensitivity analysis. Deep-Sea Res. II, 42, 1111-1149.

French, M. N., W. F. Krajewski and R. R. Cuykendall. 1992. Rainfall forecasting in space and time using a neural network. J. Hydrol., 137, 1-31.

Funahashi, K. 1989. On the approximate realization of continuous mappings by neural networks. Neural Networks, 2, 183-192.

Godfrey, J. S. and A. Schiller. 1997. Tests of mixed-layer schemes and surface boundary conditions in an Ocean General Circulation Model, using the IMET flux data set. CSIRO Marine Lab. Report (231), Australia.

Gurney, K. 1997. An Introduction to Neural Networks. UCL Press, London, 288 pp.

Haykin, S. 2002. Neural Networks: a comprehensive foundation, 2nd ed., Pearson Education Asia, Singapore, $842 \mathrm{pp}$.

Hornik, K. 1991. Approximation capabilities of multilayer feed-forward network. Neural Networks, 4, 251-257.

Hsieh, W. W. and B. Tang. 1998. Applying neural network models to prediction and data analysis in meteorology and oceanography. Bull. Amer. Meteor. Soc., 79, 1855-1870. 
Kara, A. B., P. A. Rochford and H. E. Hurlburt. 2000. An optimal definition for ocean mixed layer depth. J. Geophys. Res., 105 (C7), 16803-16821.

— 2003. Mixed layer depth variability over the global ocean. J. Geophys. Res., 108 (C3), 3079, doi: $10.1029 / 2000 J C 000736$.

Krasnopolsky, V. 1997. A neural network forward model for direct assimilation of SSM/I brightness temperatures into atmospheric models. Research Activities in Atmospheric and Oceanic Modeling, CAS/JSC Working Group on Numerical Experimentation, Rep. 25, WMO Tech. Doc. 792, 1.29-1.30.

Krasnopolsky, V., L. C. Breaker and W. H. Gemmill. 1995. A neural network as a nonlinear transfer function model for retrieving surface wind speeds from the Special Sensor Microwave Imager. J. Geophys. Res., 100, 11 033-11045.

Krasnopolsky, V., D. V. Chalikov and H. L. Tolman. 2002. A neural network technique to improve computational efficiency of numerical oceanic models. Ocean Model, 4, 363-383.

Krasnopolsky, V. M., M. S. Fox-Rabinovitz and D. V. Chalikov. 2005. New approach to calculation of atmospheric model Physics: Accurate and fast neural network emulation of longwave radiation in a climate model. Mon. Weath. Rev., 133, 1370-1383.

Krasnopolsky, V. and H. Schiller. 2003. Some neural network applications in environmental sciences part I: Forward and inverse problems in satellite remote sensing. Neural Networks, 16, 321-334.

Levitus, S. 1982. Climatological atlas of the world ocean. NOAA Prof. Pap. 13, U.S. Govt. Printing Off., Washington, D.C., 173 pp.

Lewis, M. R., M. Carr, G. Feldman, W. Esaias and C. McClain. 1990. Influence of penetrating solar radiation on the heat budget of the equatorial Pacific Ocean. Nature, 347, 543-544.

Liu, Q. H., C. Simmer and E. Ruprecht. 1997. Estimating longwave net radiation at sea surface from the Special Sensor Microwave/Imager (SSM/I). J. Appl. Meteor., 36, 919-930.

Lukas, R. and E. Lindstrom. 1991. The mixed layer of the western equatorial Pacific Ocean. J. Geophys. Res., 96, 3343-3357.

Makarynskyy, O., D. Makarynska, M. Kuhn and W. E. Featherstone. 2004. Predicting sea level variations with artificial neural networks at Hillarys Boat Harbour, Western Australia. Estuar. Coastal Shelf Sci. 61, 351-360, doi: 10.1016/j.ecss.2004.06.004.

Mao, Q., S. W. Chang and R. L. Pfeffer. 2000. Influence of large-scale initial oceanic mixed layer depth on tropical cyclones. Mon. Weather Rev., 128, 4058-4090.

Mechoso, C. R., A. W. Robertson, N. Barth, M. K. Davey, P. Delecluse, P. R. Gent, S. Ineson, B. Kirtman, M. Latif, H. Le Treut, T. Nagal, J. D. Neelin, S. G. H. Philander, J. Polcher, P. S. Schopf, T. Stockdale, M. J. Suarez, L. Terray, O. Thual and J. J. Tribbia. 1995. The seasonal cycle over the tropical Pacific in coupled ocean-atmospheric general circulation models. Mon Weather Rev., 123, 2825-2838.

Montégut, C. de B., G. Madec, A. S. Fischer, A. Lazar and D. Iudicone. 2004. Mixed layer depth over the global ocean: An examination of profile data and a profile-based climatology. J. Geophys. Res., 109, C12003, doi: 10.1029/2004JC002378.

Monterey, G. and S. Levitus. 1997. Seasonal variability of mixed layer depth of the world ocean. NOAA Atlas, NESDIS 14, Washington D.C.

Moody, J. and C. J. Darkin. 1989. Fast learning in networks of locally-tuned processing units. Neural Comp., 1, 281-294.

Niiler, P. P. and E. B. Kraus. 1977. One-dimensional models of the upper ocean, in Modeling and Prediction of the Upper Layers of the Ocean., E. B. Kraus, ed., Pergamon Press., Tarrytown, NY, $143-172$.

Obata, A., J. J. Ishizaka and M. Endoh. 1996. Global verification of critical depth theory for phytoplankton bloom with climatological in situ temperature and satellite ocean color data. J. Geophys. Res., 101, 20657-20667. 
Pozzi, M., B. A. Malmgren and S. Monechi. 2000. Sea-surface temperature and isotopic reconstructions from nannoplankton data using artificial neural networks. Palaeontologia Electronica, 3, 4-14.

Price, J., R. Weller and R. Pinkel. 1986. Diurnal cycling: observations and models of upper ocean response to diurnal heating, cooling and wind mixing. J. Geophys. Res., 91, 8411-8427.

Rao, R. R. 1986. Cooling and deepening of the mixed layer in the central Arabian Sea during MONSOON-77: Observations and Simulations. Deep-Sea Res. A, 33, 1413-1424.

Rao, R. R., R. L. Molinari and J. F. Festa. 1991. Surface meteorological and near surface oceanographic atlas of the tropical Indian Ocean. NOM Technical Memorandum. ERL AOMI-69, Miami.

Richards, K. J., M. E. Inall and N. C. Wells. 1995. The diurnal mixed layer and upper ocean heat budget in the western equatorial Pacific. J. Geophys. Res., 100, 6865-6879.

Richaume, P., F. Badran, M. Crépon, C. Mejia, H. Roquet and S. Thiria. 2000. Neural network wind retrieval from ERS-1 scatterometer data. Neurocomputing, 30(1-4), 37-46.

Ripley, B. D. 1997. Pattern Recognition and Neural Networks, Cambridge University Press, 403 pp.

Rudnick, D. L., R. A. Weller, C. C. Eriksen, T. D. Dickey, J. Marra, and C. Langdon. 1997. One year moored observations of the Arabian Sea. EOS Trans. AGU, 78, 120-121.

Schiller, A., J. S. Godfrey, P. McIntosh and G. Meyers. 1997. A Global Ocean General Circulation Model for Climate Variability Studies. CSIRO Marine Lab. Report (227), Australia.

Schroder Th., J., Fischer, M., Schaale, and F. Fell. 2002. Artificial neural network based atmospheric correction algorithm: Application to MERIS data, Proc. Int. Soc. Opt. Eng. (SPIE), 4892, Hangzhou, China.

Singh, R., B. G. Vasudevan, P. K. Pal and P. C. Joshi. 2004. Artificial Neural Network Approach for Estimation of Surface Specific Humidity and Air Temperature using Multifrequency Scanning Microwave Radiometer. Proc. Indian Acad. Sci. (Earth Planet. Sci.), 113, 1, 89-101.

Sutton, P. J., P. F. Worcester, G. Masters, B. D. Cornuelle and J. F. Lynch. 1993. Ocean mixed layers and acoustic pulse propagation in the Greenland Sea. J. Acoust. Soc. Am., 94, 1517-1526.

Tangang, F. T., W. W. Hsieh, and B. Tang. 1998. Forecasting the regional sea surface temperatures of the tropical Pacific by neural network models, with wind stress and sea level pressure as predictors. J. Geophys. Res., 103, 7511-7522.

Thomson, R. E. and I. V. Fine. 2003. Estimating mixed layer depth from oceanic profile data. J. Atmos. Oceanic Technol., 20, 319-329.

Tolman, H. L., V. M. Krasnopolsky, and D. V. Chalikov. 2005. Neural network approximations for nonlinear interactions in wind wave spectra: Direct mapping for wind seas in deep water. Ocean Model., 8, 253-278.

Weller, R. A., M. F. Baumgartner, S. A. Josey, A. S. Fischer and J. C. Kindle. 1998. Atmospheric forcing in the Arabian Sea during 1994-1995: Observations and comparisons with climatology and models. Deep-Sea Res. II, 45, 1961-1999.

Received: 15 August, 2005; revised: 9 June, 2006. 